\title{
Hospital Costs and Unexpected Demand: The Case of Greece ${ }^{\S}$
}

\author{
Zoe Boutsioli* $^{*}$
}

Health Research Unit, Athens Institute for Education and Research (ATINER), Athens, Greece

\begin{abstract}
Demand for hospital inpatient care varies in a consistent way. However, a part of this variability is unpredictable. Hospitals react to this situation by holding standby capacity in order to be prepared to meet unanticipated surges in demand. This paper examines the production responses to unexpected hospital demand on a sample of Greek public hospitals over the period 2001-2005. The hospital output is measured by the number of inpatient admissions, distinguishing them into elective and emergency. The unexpected demand is measured as the difference between actual emergency admissions and forecasted emergency admissions using an Autoregressive Moving Average model. The results support the hypothesis that production reactions to unexpected demand have a significant impact on hospital costs.
\end{abstract}

Keywords: Hospital, production, cost, uncertainty, demand, Greece.

\section{INTRODUCTION}

Demand for hospital inpatient care varies in a consistent way - it reduces during weekends, national holidays and in summer months. However, a part of this variability is unpredictable. Hospitals react to this situation by holding standby capacity in order to be prepared to meet unanticipated surges in demand. Hospital administrators are motivated to maintain this reserve capacity for many reasons. First, the public pressure for health care availability forces hospitals to avoid waiting lists and to avert turning away patients $[1,2]$. Second, the seasonality is an important feature of hospital admissions [3-10]. Third, it is assumed as a quality indicator $[11,12]$.

The hospital's production of standby capacity affects positively on total variable hospital costs. However, up to the 1990's unexpected demand has been overlooked in studies of the structure of hospital costs, although it is an important characteristic of hospital care [13]. The weakness of empirical studies to include the provision of standby capacity by hospitals to serve unexpected demand has led to the conclusion that hospitals over-invest in capacity and equipment [14]. Also, Hughes and McGuire [15] have pointed out that cost inefficiencies within hospitals may be explained by the existence of uncertain demand.

More recently empirical researchers have attempted to estimate the magnitude of this impact on hospital costs. Most have found a positive, small but statistically significant effect of the unexpected hospital demand on cost; independently of the country setting these studies were conducted. Although the initial cause for undertaking such a study differs from country to country the final goal is 'one': the cost cutting. In this section, we review the few empirical

*Address correspondence to this author at the Health Research Unit, Athens Institute for Education and Research (ATINER), 20 Omirou Street, Kolonaki 10672 Athens, Greece; Tel: +30 697080 6321; Fax: +30 21036 18 314; E-mail: zb5@atiner.gr

${ }^{\S}$ This paper is part of my $\mathrm{PhD}$ thesis at University of Kent, UK. studies which discuss the issue of demand uncertainty and its impacts on hospital costs. Studies exist only for USA, UK, Belgium and Spain. In the USA, the drive, especially after the certificate-of-need regulation $(\mathrm{CON})$ in the middle of 1970 's and the federal antitrust legislation, was the closure or the consolidation of hospital units for cost savings [13]. Additionally, an argument usually advanced in merger debate in the USA is that bigger hospitals are more efficient. Thus, a way that such efficiencies could be achieved is through declines in demand variability [1]. As highlighted by Lynk [16], merged hospitals, across their shared services, would possible face lower unpredictability in demand relative to the mean, which may lead to lower costs. In the UK, under a publicly National Health Service (NHS) the driving force was the limited hospital bed capacity in a tax financed system [15] in combination with a consecutive increase of emergency hospital admissions as part of overall admissions [17]. Hospitals in the UK do respond to demand uncertainty and such a result is of paramount importance for reimbursement and regulatory strategies in the hospital sector. Hospital fees and reimbursement levels are based on the accurate estimation of costs and understanding of their structures. Thus, fees should be set at a level that gives the proper incentives to hospitals to hold standby capacity where this is an efficient reaction to uncertain demand [15].

In Belgium, the health care system is characterised by a compulsory health insurance with a wide coverage. For Smet [14], the driving force for conducting such a study was to test if the hypothesis of cost minimization with exogenous output quantities and input prices can be supported by the Belgian hospital sector. In short, Smet [14] supposed that cost minimization might be a valid assumption because the Belgian health care system applies more stringent reimbursement policy in order to contain the total health care costs. Although, results from the econometric estimation on hospital cost functions confirm that hospitals tend to overinvest in capacity and that they therefore do not operate in their long-run cost-minimizing level of output. To explain this finding, researchers have analyzed the impact of 
stochastic demand on cost. The hypothesis is that hospitals will attempt to keep excess demand below a certain maximum target and that they therefore must provide through standby capacity. This standby capacity should be treated as a service provided by the hospital. Not taking into account this feature when estimating a hospital cost function will lead to biased results, suggesting that hospitals are inefficient [14].

Knox Lovell et al. [18] from Spain observed that the literature on the effect of demand uncertainty on public hospital costs and excess capacity has not taken into account the role of expense preference behavior. Thus, they expanded the model of Rodriquez-Alvarez and Knox Lovell [19] and enriched their analysis by incorporating demand uncertainty into the technology to account for the hospital activity of providing standby capacity or insurance against the unexpected demand. Rodriquez-Alvarez and Knox Lovell [19] studied the excess capacity in NHS of Spain hospitals, which have the characteristics of a bureaucracy. They observed persistent allocative inefficiency ${ }^{1}$ in variable inputs and overcapitalization in Spain hospitals, and hence suggested that the hospital sector in Spain is not in long-run equilibrium and that these adjustments in variable inputs and capital equipment investments are necessary to control hospital cost. Knox Lovell et al. [18] argued that both demand uncertainty and expense preference behavior may affect public hospital costs and excess capacity and that ignoring either of these effects may lead to biased parameter estimates and misleading inference.

Different methods have been used to estimate the demand uncertainty. Some researchers have used a direct measure to capture demand uncertainty incorporating this into the cost function, while others have applied a measure of standby capacity that hospitals hold in order to service unexpected demand. In earlier studies, Friedman and Pauly $[11,12]$ employed the ratio of forecasted to actual hospital admissions. This method was criticised by Hughes and McGuire [15] who argued that if a ratio is estimated, the level of uncertainty is not captured. Additionally, such a measure of demand uncertainty reflects the expected fluctuations in demand, i.e. the ones the hospitals can predict, and thus, if hospitals can accurately predict the fluctuations then there is no reason to expect this to have an effect on hospital costs. Gaynor and Anderson [21] used the first two moments: the mean and the standard deviation of the distribution of annual demand conditional on past values to estimate hospital unexpected demand. Hughes and McGuire [15] modelled a simple autoregressive process assuming demand expectations are related to prior demand knowledge. Thus, the level of uncertainty faced by a hospital was defined as the difference between the observed and the forecasted emergency demand. Smet [14] used a waiting time indicator to proxy standby capacity held by hospitals to serve unexpected demand in Belgium. The indicator is derived from queuing theory and develops the commonly

\footnotetext{
${ }^{1}$ According to McPake et al. [20] allocative efficiency is defined as "Productive activity has been allocated to those products which consumers value in excess of their cost (marginal cost has been equated to marginal value)".
}

used inverse of the occupancy rate. A limitation of previous studies is the dependence on annual, quarterly or monthly data of hospital demand in order to formulate the hospital's reaction to unexpected demand. Recently, empirical works have employed daily data to estimate demand variations for hospital care [22, 23]. Slightly different, Baker et al. [1] measured daily occupancy in California hospitals and examined variations in hospital utilization at the daily level. To do so they have utilized the mean and the standard deviation of the demand facing the hospital.

In Greece the issue of hospital efficiency is not high in the political agenda. Only recently the Ministry of Health has shown an interest on this issue. With the law 2889 in 2001, the government of the socialist party (PASOK) attempted to increase the efficiency of health care services by reducing the cost of producing an output of a given volume, quality and technology ${ }^{2}$. Even in the academic community, the issue of hospital efficiency is not a research priority. Only recently, a number of empirical studies assessed the efficiency of hospital operations in Greece [24, 28-31]. A significant conclusion which emerges from this literature is that public hospitals in Greece present significant inefficiencies and there is significant room for economic improvements. Among others, it has been found that the Greek public hospitals present a $14 \%$ excess bed capacity attributable to operating slack [29]. According to the previous mentioned international evidence this excess capacity might be an efficient reaction by the Greek hospital managers to serve the unexpected inpatient care or this is due to expense preference behavior [18]. Further research is needed to answer the above questions.

In this paper, we provide estimates of unexpected demand using daily emergency admissions data from 10 public hospitals in Greece during the period 2001-2005. Then, these measurements are used to estimate the impact of unexpected demand on total variable hospital cost. Strong statistically significant effect of unexpected hospital demand on costs is found. Excluding this introduction, the rest of the paper is as follows: Section 2 provides the model specification for both unexpected demand and hospital costs. Section 3 presents the data sources and descriptive statistics of the dependent and explanatory variables, including the unexpected demand variable. Section 4 contains the regression results of the various model specifications of the hospital cost functions and provides measures of economies of scale and scope along with their significance for the efficiency of hospitals. Section 5 concludes, emphasizing the implications of the empirical results for social policy makers and public hospital administrators.

\section{MATERIALS AND METHODOLOGY}

Hospital emergency admissions are used as the dependent variable to estimate unexpected demand. ARMA $^{3}$

\footnotetext{
${ }^{2} \mathrm{~A}$ number of papers have described and criticized the 2001 health reforms underwent the Greek National Health System (NHS). Among others see: Aletras et al. [24], Carpenter [25], Mossialos et al. [26], Tountas et al. [27]. ${ }^{3}$ This method has been extensively used both in health care services (Jones et al. [23], Linares and Diaz [3], Hisnack [32], Diaz et al. [4], Hussain et al.
} 
is a regression model where the explanatory variables are lags of the dependent variable. According to this model, the unexpected demand is based on a residual estimate of forecasted daily emergency demand. Thus, the level of unexpected demand faced by a hospital is defined as the difference between realised and forecasted emergency demand, gained from ARMA forecasting model. In its general form, the mathematical expression of an ARMA model can be represented as follows:

$\mathrm{Q}_{\mathrm{t}}=\sum_{\mathrm{i}=1}^{\mathrm{p}} \varphi_{\mathrm{i}} \mathrm{Q}_{\mathrm{i}-\mathrm{t}}+\sum_{\mathrm{i}=1}^{\mathrm{q}} \theta_{\mathrm{i}} \varepsilon_{\mathrm{i}-\mathrm{t}}+\varepsilon_{\mathrm{t}}$

where $\mathrm{Q}_{\mathrm{t}}$ are hospital emergency admissions in day ( $\left.\mathrm{t}\right), \varphi_{1}, \varphi_{2}$ ... $\varphi_{\mathrm{p}}$ are the parameters of the autoregressive term of the model, $\theta_{1}, \theta_{2} \ldots \theta_{\mathrm{q}}$ are the parameters of the moving average term and $\varepsilon_{\mathrm{t}}$ is the error term. The error term is generally assumed to be independent identically-distributed random variables (i.i.d.) sampled from a normal distribution with zero mean: $\varepsilon_{\mathrm{t}} \sim \mathrm{N}\left(0, \sigma^{2}\right)$ where $\sigma^{2}$ is the variance. In an ARMA hospital admissions model the first step is to choose $\mathrm{p}$ and $\mathrm{q}$, i.e. how many lags to use from past daily admissions and how many lags of past errors in predicting the variable should be included. In practice, it is desirable to find the smallest values of $p$ and $q$ which provide an acceptable fit to the data. The second step is to estimate the parameters $\varphi$ and $\theta$. ARMA models can in general be fitted by maximum likelihood estimation to find the values of the parameters which minimize the error term. This error term provides an estimate of unexpected hospital demand. The AR and MA part of the ARMA model explain variations in the daily hospital admissions that can be forecasted by hospital managers. The $\varepsilon_{t}$ term measures the unexpected demand in day (t); it is the error that managers make when they do their forecasts based on the ARMA model ${ }^{4}$. It is the annual variations in these forecast errors that provide a measure of unexpected demand to be used in the hospital cost function. We have also tried the AR structure, applied by Hughes and McGuire [15] but the applied ARMA model has provided better fit to the data. Contrary to Hughes and McGuire [15] that use monthly hospital admissions data, we apply daily data and this might explain why an ARMA process fits our data better than an AR process.

The short run cost function is a model that contains measures of unexpected demand and a number of shift cost variables. This specification is similar to what Hughes and McGuire [15] used in their empirical variable cost model estimation of the UK hospitals. In its general form, the cost model specification relates total variable hospital cost to a number of explanatory variables:

[5], Jones et al. [10] and in other empirical practices i.e. electricity [33], transportation research [34] and in criminology [35].

${ }^{4}$ All these models are ad hoc models in the sense that AR and MA terms are used to best explain the given Data Generated Process. There is no one ARMA or one ARIMA or one AR model that fits all time series. These model(s) use criteria for selecting what is considered an optimal lag structure. In the case of this model, the ARMA gives better results and these are evaluated using the Akaike info criterion (AIC) and the Schwarz criterion (SIC). For further discussion of how to apply these time series models see Chatfield [36] and Anderson [37].
$\mathrm{TVC}=\mathrm{f}$ \{unexpected demand, admissions (emergency + elective), input prices, beds, shift variables\}

where TVC is total variable hospital cost deflated by the Consumer Price Index (CPI), in 2005 prices. Unexpected demand is the variable that captures demand uncertainty and is measured by emergency admissions. This measure is estimated as the difference between actual emergency admissions and expected emergency admissions, using a univariate model. Hospital admissions measure output, which is separated into emergency and elective admissions, in order to test their marginal impact on cost. We can hypothesize that output variable is most probably exogenous $[14,38,39]$ given that in the Greek public hospitals patients do not pay directly for the services they receive. Thus, prices and outputs are determined by different processes, making the output variable a true exogenous variable in the total variable cost variable. A wage rate for public sector (services) is used deflated by the Consumer Price Index (CPI), in 2005 prices. Hospital beds are divided into those devoted to elective and emergency services. As in Hughes and McGuire [15], we assume that the occupancy rate for the elective services is $100 \%$, given that exist extensive waiting lists in the Greek NHS. Thus, the elective beds are based on elective admissions and the length of stay in that sector, while the emergency beds are those used for emergency and unexpected demand. The latter contains an element of standby capacity. The shift variables include a number of hospital characteristics and dummy variables that account for changes in total variable hospital costs. The choice of which shift variables to include in the model is determined by statistical criteria, such as appropriate sign of the estimated coefficients, statistical significance or t-statistic, the coefficient of determination $\left(\mathrm{R}^{2}\right)$, and the overall significance of the explanatory variables (F-statistic). Carey [40] reported that the other explanatory or shift variables include factors that have been found by previous researchers to be significant in explaining cost variations. We tested a number of such shifters but only the teaching dummy variable was statistically significant. Teaching status means that within the hospital exist one or more teaching medical clinics which collaborate with the Medical Department of the University of Athens and they (the hospitals) have a residency programme. Other variables examined include the average length of stay, outpatient visits, inverse of the occupancy rate and hospital location.

\section{Data Sources}

This study was conducted using panel data from 10 general public hospitals in Athens, Greece over the period 2001-2005. They all keep separate elective and emergency admissions records. Admissions data were collected on a daily basis, while cost data were collected on an annual basis.

\section{Unexpected Hospital Demand}

To estimate unexpected hospital demand, we use the emergency hospital admissions series. First, we test for stationarity of the daily emergency admissions. The standard Augmented Dickey-Fuller test (ADF) that is commonly used 
to test for a unit root has proved that the null hypothesis of unit root is rejected at the $1 \%$ level of significance implying that the series are stationary at the level for all hospitals. Then, we have selected the best ARMA model specification, based on the criteria proposed by Akaike and Schwarz. The lower the values of the Akaike info criterion (AIC) and Schwartz criterion (SIC), the most appropriate the ARMA model $^{5}$.

Each ARMA process (i.e. one for each hospital per year) provides an estimate of the residual $\left(\varepsilon_{t}\right)$, which is the unexpected part of emergency daily admissions. According to the theory, the residuals have a zero mean and a constant standard deviation. To estimate annual variations of unexpected demand we have used the positive values of forecast errors. The forecast errors are positive when actual (emergency admissions) are more than the fitted. We call this excess demand for unexpected admissions.

Table 1 presents data on the variability of emergency admissions when the actual emergency admissions are above the ones predicted by the model. In that case, emergency admissions are greater than forecasted and then hospital managers are forced to turn away patients or treat them with lower than expected quality, i.e. put them in beds in the corridors of the hospital ${ }^{6}$. Differences exist among hospitals and over the period, with the former being much larger than those over the 5-year period.

Table 1. Variations in Unexpected Daily Hospital Demand

\begin{tabular}{|c|c|c|c|c|c|c|}
\hline & Hospital & $\mathbf{2 0 0 1}$ & $\mathbf{2 0 0 2}$ & $\mathbf{2 0 0 3}$ & $\mathbf{2 0 0 4}$ & $\mathbf{2 0 0 5}$ \\
\hline \hline 1 & A & 10.6 & 11.5 & 10.6 & 10.8 & 7.9 \\
\hline 2 & B & 8.8 & 8.7 & 8.0 & 9.0 & 6.6 \\
\hline 3 & C & 3.4 & 4.6 & 4.3 & 5.1 & 6.0 \\
\hline 4 & D & 11.7 & 13.7 & 14.5 & 14.2 & 10.5 \\
\hline 5 & E & 9.6 & 12.4 & 10.6 & 9.0 & 10.0 \\
\hline 6 & F & 7.1 & 9.1 & 9.6 & 10.7 & 10.2 \\
\hline 7 & G & 2.5 & 2.7 & 2.4 & 2.2 & 2.3 \\
\hline 8 & H & n/a & 6.7 & 7.1 & 6.6 & 4.5 \\
\hline 9 & I & 4.5 & 5.2 & $\mathrm{n} / \mathrm{a}$ & $\mathrm{n} / \mathrm{a}$ & $\mathrm{n} / \mathrm{a}$ \\
\hline 10 & J & 10.4 & 10.6 & 12.6 & 9.6 & 9.4 \\
\hline
\end{tabular}

Note: The number of daily admissions is 1826 for all hospitals (five-year data) with the exception of No 8 (1461 observations-days) and No 9 (730 observations-days).

In Table 2 we have estimated the unexpected demand on an annual basis. The estimates are provided per year and per hospital. These annual estimates are used in the next section

${ }^{5}$ Both AIC and SIC are two closely related alternative statistical measures of goodness-of-fit of an ARMA model. The fit improves as the residuals become smaller. In our case, we used both the AIC and the SIC tests to determine the optimal lag structure [36].

${ }^{6}$ If unexpected emergency admissions are greater than the ones forecasted by the model, then the result will be an overcrowded emergency department and inpatient care delivery. A number of studies have documented that overcrowding has detrimental effects on the quality of care delivery; see Vieth and Rhodes, 2006; Pines et al., 2007a; Pines et al., 2007b; Pines \& Hollander, 2008; Fee et al., 2007. as one of the determinants of the annual variations of total hospital costs from 2001 to 2005.

Table 2. Annual Unexpected Hospital Demand

\begin{tabular}{|c|c|c|c|c|c|c|}
\hline & Hospital & $\mathbf{2 0 0 1}$ & $\mathbf{2 0 0 2}$ & $\mathbf{2 0 0 3}$ & $\mathbf{2 0 0 4}$ & $\mathbf{2 0 0 5}$ \\
\hline \hline 1 & A & 1629 & 2093 & 1870 & 1703 & 1432 \\
\hline 2 & B & 1123 & 1237 & 1182 & 1243 & 920 \\
\hline 3 & C & 437 & 583 & 542 & 690 & 937 \\
\hline 4 & D & 2243 & 2497 & 2437 & 2716 & 2801 \\
\hline 5 & E & 1467 & 1774 & 1367 & 1559 & 920 \\
\hline 6 & F & 1209 & 1551 & 1598 & 2058 & 1715 \\
\hline 7 & G & 244 & 249 & 249 & 206 & 248 \\
\hline 8 & H & n/a & 1163 & 1287 & 871 & 940 \\
\hline 9 & I & 817 & 945 & n/a & n/a & n/a \\
\hline 10 & J & 2067 & 2309 & 2689 & 2098 & 2252 \\
\hline
\end{tabular}

Note: The number of daily admissions is 1826 for all hospitals (five-year data) with the exception of No 8 (1461 observations-days) and No 9 (730 observations-days).

\section{Descriptive Statistics}

Summary statistics (mean and standard deviation) of the dependent and the explanatory variables are listed in Table $\mathbf{3}$. The average total variable hospital cost is 42.5 million euro with a standard deviation of 32 million euro measured in 2005 prices. This cost paid, on average, for 25,910 annual total admissions and 86,211 outpatient visits. Elective admissions accounted for $42 \%$ (10,999 admissions) and emergency admissions accounted for $58 \% \quad(14,910$ admissions) of the total hospital admissions.

Table 3. Descriptive Statistics, 2001-2005 $(\mathrm{N}=46)$

\begin{tabular}{|c|c|c|}
\hline Variable & Mean & Standard Deviation \\
\hline \hline $\begin{array}{c}\text { Total variable cost } \\
(€ 000 \text { in 2005 prices) }\end{array}$ & 42,580 & 31,494 \\
\hline Unexpected demand & 1,395 & 730 \\
\hline Total admissions & 25,910 & 13,643 \\
\hline Elective admissions & 10,999 & 7,735 \\
\hline Emergency admissions & 14,910 & 9,448 \\
\hline Outpatient visits & 86,211 & 63,364 \\
\hline Total beds & 479 & 226 \\
\hline Elective beds & 153 & 111 \\
\hline Emergency beds & 327 & 176 \\
\hline $\begin{array}{c}\text { Inverse of the emergency } \\
\text { occupancy rate }\end{array}$ & 2.02 & 1.01 \\
\hline Real wage cost (2005=100) & 99.35 & 2.47 \\
\hline Teaching dummy variable & 0.43 & 0.50 \\
\hline
\end{tabular}

Unexpected demand, measured as the sum of the positive value of all forecast errors - is 1,395 admissions with a 
standard deviation of 730 admissions. Hospital administrators and health planners make an average annual error of 1,395 admissions when they forecast emergency admissions. This annual error is high and it is expected to impose a great cost on hospital.

The average hospital in the sample has 479 beds but there is a high variability as this is measured by the standard deviation of 226 beds. The average number of emergency beds is 327 and 153 for elective beds. The variability of emergency hospital beds is higher (176) than for elective beds (111).

The emergency occupancy rate is defined as the ratio of emergency admissions multiplied by the average length of stay over the annual emergency bed-nights (number of emergency beds multiplied by 365) and it is jointly determined by the number of patients arriving in the hospital for emergency treatment per year, the average length of stay $^{7}$, and the number of beds allocated to the emergency sector. In the regression analysis, we use the inverse of the emergency occupancy rate, which is related to the fixed capacity allocated to unexpected demand. This variable refers only to the emergency sector including an element of reserve capacity. The average value of the inverse of the emergency occupancy rate is 2 , which implies that $50 \%$ of the emergency hospital capacity is not used (Table 3 ). The maximum value of the inverse of the occupancy rate is 5.4, i.e. over $80 \%$ of the emergency hospital capacity remains unused. The minimum value is estimated as one, which means that hospitals use all their emergency capacity. In this case, there is full utilization of hospital emergency beds.

Two more explanatory variables are reported in the regression results. First, an index of the wage cost is used deflated by the CPI (Consumer Price Index). The mean value of wage index is 99.35 with a standard deviation of 2.47 . Second, a dummy variable to account for the teaching status of the hospital is used. In 4 public hospitals out of 10 operated, at least, one teaching medical clinic during the 5year period examined.

\section{RESULTS}

The theoretical accepted functional form of a cost function is a cubic polynomial function that gives rise to a U-shaped unit cost curves. These types of cost curves are Sshaped and they are consistent with the cost efficiency behavior. A number of functional forms were applied to both the dependent and explanatory variables. The results favour a cubed root transformation, which is consistent with the theoretical cost function of S-shape. Fig. (1) shows the mapping of the cubed root total variable cost to total, elective and emergency admissions, respectively.

It also appears from the scatter diagrams of Fig. (1) that the variance of the total variable cost increases with increasing values of total admissions and emergency admissions, suggesting that the Ordinary Least Square (OLS) regressions might violate the assumption of

${ }^{7}$ It is used the average length of stay (ALOS) for all inpatient services provided by the hospital, because the ALOS for only emergency patients was not available. homoscedasticity of the error terms. Parameter estimates remain unbiased (their value is a good approximation of the true parameter values) but are less efficient, i.e. they have high standard errors rejecting their statistical significance. To rectify this, we have applied the Generalized Least Square (GLS) regression method which gives the same unbiased results as the OLS. However, unlike OLS, the GLS provides efficient estimates of the parameters of the model.

(a)

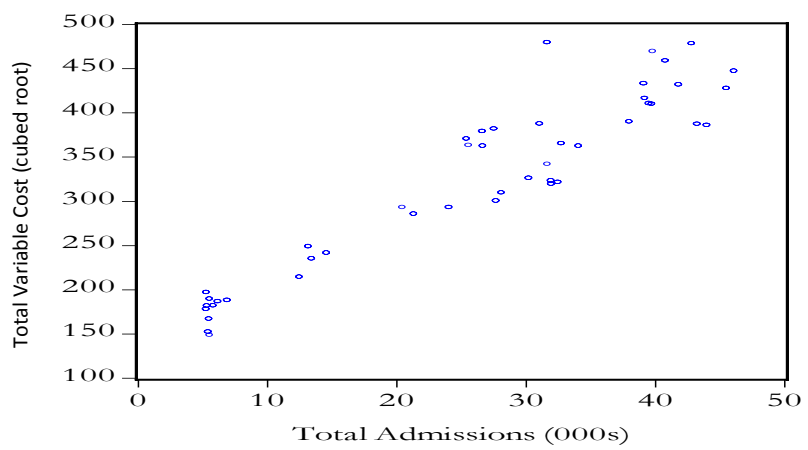

(b)

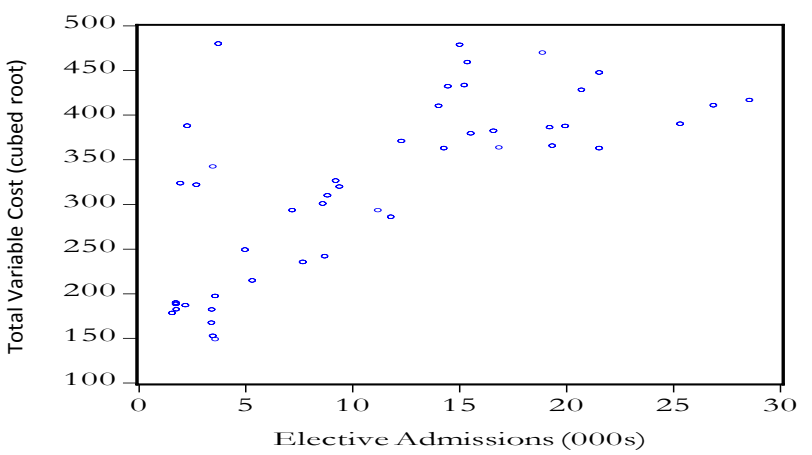

c)

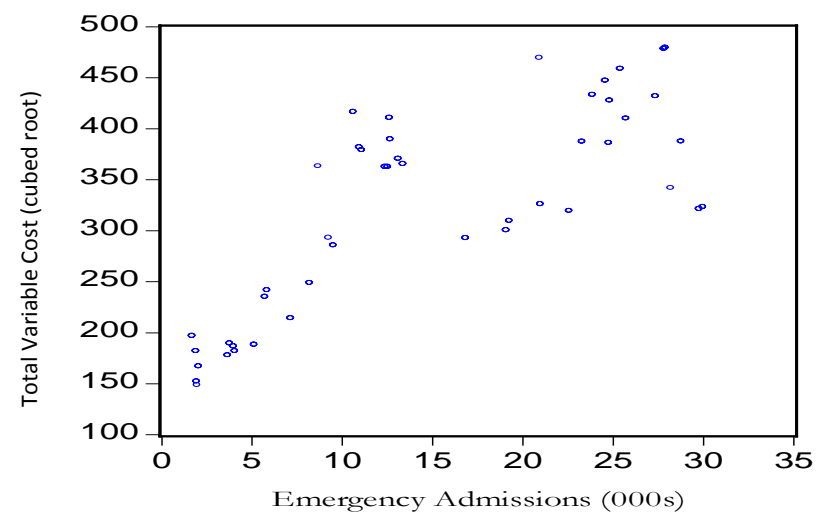

Fig. (1). (a) Total variable cost and total admissions, (b) total variable cost and elective admissions, (c) total variable cost and emergency admissions.

The empirical findings of the hospital cost model are presented in Table 4. The reported estimates are the GLS 
with period weights and are consistent with the theoretical foundations of the hospital cost functions.

Our model specification includes the sum of unexpected demand that exceeded the level of demand forecasted by the model. This presents a considerably high goodness of fit and high explanatory power. The coefficient of determination equals to $97 \%$ and the overall significance of the explanatory variables has an $\mathrm{F}$ value of 157.

All explanatory variables have the expected sign. Unexpected demand has a strong positive impact on total hospital variable cost, supporting the hypothesis that production reactions to unexpected demand have a significant impact on hospital costs.

Emergency and elective admissions have a positive impact on total variable cost and they are statistically significant at the $10 \%$ or lower level. The interaction output term has a negative statistical significant impact on total variable costs.

One would expect the impact of emergency admissions on total variable hospital cost to be higher than that of elective admissions. However, we have found a similar impact. This might be explained by the fact that it is a common practice in the Greek public hospital admission process the characterization of an elective case as an emergency one in order to bypass the long waiting list for elective admissions [41]. This is something done in accordance with all interested parties - patients, doctors and officers - and with the tolerance of hospital administrators. The only that looses in this process is the patient who pays out-of-pocket and 'under the table' money to all those involved in the phoney characterization of an elective admission as an emergency one. This process is expected to mitigate the impact of unexpected demand. However, and given that the hospital first serves the real emergency cases and then, if there is space, admits the other cases, this might appear paradoxical but this practice improves hospital efficiency. Of course, if the phoney emergency admissions are given priority over the true emergency admissions, efficiency is served but at the social cost of undermining the provision of health services according to need.

The next two explanatory variables account for the fixed capacity impact on hospital costs. It is measured by staffed beds of hospital. Consistent with the output separation into elective and emergency admissions, beds are separated into the number of beds allocated to elective sector and the ones allocated to emergency sector. Elective beds have a stronger marginal impact on costs relative to emergency beds but a Wald test cannot reject the hypothesis of no difference $\left(\chi^{2}=\right.$ $1.71, \mathrm{p}=.1906)$. The statistical significance of the beds variable indicates that hospitals were not at their long run equilibrium. A similar conclusion was reached by Aletras [42] for public hospitals in Greece.

The last two explanatory variables are the labour input price and a dummy variable to account for the teaching status of the hospital. As far as the impact of wage rate on hospital variable cost is concerned, it is positive and statistically significant.
The results on teaching hospital dummy variable suggest that the existence and operation of teaching clinics collaborated with the Medical Department of the University of Athens is a significant cost-driving factor for public hospitals that run a residency programme due to the higher case load and the education mission. This result is consistent with other hospital cost function studies [14]. If teaching is a proxy for quality, then the positive strong impact may indicate that the output explanatory variables are not capturing the entire spectrum of hospital output. On the other hand, teaching is by itself another dimension of the hospital's output because medical treatments bear additional costs from a teaching point of view [43].

\section{Table 4. Cost Function Econometric Results}

\begin{tabular}{|c|c|c|}
\hline Variable & Coefficient & t-Value \\
\hline Constant & -438.75 & $-2.97 *$ \\
\hline $\begin{array}{c}\text { Unexpected Demand } \\
\text { (sum of positive residuals) }\end{array}$ & 0.029 & $3.23 * * *$ \\
\hline Elective admissions & 0.0040 & $1.92 *$ \\
\hline Emergency admissions & 0.0032 & $2.32 * *$ \\
\hline $\begin{array}{l}\text { Interaction term } \\
\text { (elective } \mathrm{x} \text { emergency admissions) }\end{array}$ & $-1.97 \mathrm{E}-7$ & $-7.30 * * *$ \\
\hline Emergency beds & 0.14 & $2.42 * *$ \\
\hline Elective beds & 0.31 & $2.83 * * *$ \\
\hline Wage index & 5.60 & $3.61 * * *$ \\
\hline Teaching hospital dummy variable & 46.78 & $5.37 * * *$ \\
\hline $\mathrm{N}$ & 46 & \\
\hline $\mathrm{R}^{2}$ & 0.9714 & \\
\hline $\mathrm{R}^{2}$-adjusted & 0.9652 & \\
\hline F-Statistic & 157.19 & \\
\hline
\end{tabular}

\section{Marginal Costs}

Table 5 provides marginal cost estimates of emergency admissions, elective admissions and other variables of interests. The marginal costs of emergency and elective admissions are calculated using the estimated coefficients on the admissions variables in the cost equation and the corresponding beds variables. All estimates are based on the mean value of the variables. The marginal cost of unexpected emergency admissions is $€ 6,132$. The marginal cost of an emergency and an elective admission are $€ 1,145$ and $€ 1,368$, respectively. These findings are similar with those found by Smet [14] for Belgian hospitals in 1997. His findings range from $€ 1243$ to $€ 15542$. He distinguishes between different types of hospital stay depending on hospital departments.

The cost of an empty hospital bed is measured by the marginal impact of the inverse of the occupancy rate. It represents the marginal cost of an increase in fixed capacity 
(a fall in the occupancy rate). Following Gaynor and Anderson [21], we multiply the marginal cost of increased fixed capacity by the mean value of the inverse of the occupancy rate and divide it by the number of beds. The result gives the cost of an empty bed. Our estimate of the short run cost of an empty bed is $€ 63,478$ at 2005 prices. The cost of an emergency bed is 174 euro, which is similar to what Hughes and McGuire found [15].

Table 5. Marginal Costs

\begin{tabular}{|c|c|}
\hline Variable & Marginal Costs $(\boldsymbol{\epsilon})$ \\
\hline \hline Unexpected Emergency Admissions & 6,132 \\
\hline Emergency admissions & 1,145 \\
\hline Elective admissions & 1,368 \\
\hline Emergency bed & 48,202 \\
\hline Elective bed & 126,521 \\
\hline Cost of an empty bed & 63,478 \\
\hline Cost per day of empty emergency bed & 174 \\
\hline
\end{tabular}

\section{Economies of Scale and Economies of Scope}

The empirical results can be used to calculate economies of scale for a short run cost function as proposed by Caves et al. [44] and applied to hospital costs functions that incorporated demand uncertainty by Gaynor and Anderson [21], and Hughes and McGuire [15]:

$\mathrm{S}=\left\{1-\Sigma\left(\delta \ln T V C / \delta \ln \mathrm{B}_{\mathrm{i}}\right)\right\} / \Sigma_{\mathrm{i}}\left(\delta \ln \mathrm{TVC} / \delta \ln \mathrm{Q}_{\mathrm{i}}\right)$

where $B_{i}$ represents elective and emergency beds and $Q_{i}$ indicates admissions.

The estimation of $\mathrm{S}$ is based on the observed value of beds and it is a measure of short run economies of scale. The estimates are based on a logarithmic estimation. We found $\mathrm{S}=0.88$ which is slightly lower than the value found by Gaynor and Anderson [21] and Hughes and McGuire [15] of 1.02. This method assumes that economies of scale are the same at all levels of bed capacity and number of admissions. However, this is not the case and hospitals may differ to the extent that they exploit all economies of scale.

An alternative estimation of economies of scale is used. For simplicity reasons, we use the regression results of a simple total admissions regression equation without the input price $^{8}$ (not reported in Table 4). Hospitals are grouped into different bed sizes given in Column 1 of Table 6. We also report the corresponding number of admissions per group of bed hospital capacity. The last three columns of Table 6 give the measurements of marginal cost, average cost and the ratio of marginal to average cost per group of hospital capacity.

Economies of scale exist if the average cost is declining with output levels. The results of Table $\mathbf{6}$ show that at low

\footnotetext{
${ }^{8}$ The coefficient results of the simple total admission regression model: $\mathrm{C}=$ $-312.17+0.0068 *($ ELADM+EMADM $)+4.62 *$ WAGE_RATE. The results are statistically significant at $1 \%$ level.
}

bed capacity and output, the marginal cost is below the average cost by up to 300 beds. Thus, at this level of output hospitals experience increasing returns to scale. Constant returns to scale are obtained at 10,300 annual admissions. For higher levels of output, the marginal cost is higher than the average cost, indicating diseconomies of scale. The optimal number of admissions, i.e. the number of admissions that minimize the long run average cost is 10,300 with an average cost of 980 euro per admission. The average hospital of our sample has 479 beds which correspond to 25,909 annual admissions. At this level of capacity and admissions, there are diseconomies of scale. This is similar to the result obtained with the logarithmic measurement of economies of scale.

Table 6. Economies of Scale and Hospital Capacity

\begin{tabular}{|c|c|c|c|c|}
\hline Number of Beds & Average Admissions & MC & AC & MC/AC \\
\hline \hline $100-200$ & 5,432 & 696 & 1,110 & 0.63 \\
\hline $200-300$ & 7,921 & 835 & 1,002 & 0.83 \\
\hline $300-400$ & 14,010 & 1,231 & 1,012 & 1.22 \\
\hline $500-600$ & 27,501 & 2,378 & 1,386 & 1.72 \\
\hline $600-700$ & 34,873 & 3,163 & 1,676 & 1.89 \\
\hline $700-800$ & 35,914 & 3,283 & 1,721 & 1.91 \\
\hline $800-1000$ & 41,007 & 3,902 & 1,953 & 2.00 \\
\hline Average=479 & 25,909 & 2,223 & 1,329 & 1.67 \\
\hline Optimal & 10,300 & 980 & 980 & 1.00 \\
\hline
\end{tabular}

The results presented in Table $\mathbf{6}$ show differences among Greek hospitals in terms of their economies of scale performance. Adang and Wensing [45] found similar results. They estimated economies of scale of 33 hospitals in Holland. Their paper looked at possible differences between long run and short run efficiency of innovative technologies in health care by exploring diseconomies of scale in Dutch hospitals. In 18 hospitals they found decreasing returns to scale, in 11 constant, and in 4 hospitals increasing returns to scale.

The measurements presented in Table 6 show that the hospital sector in Greece is characterized by a production technology that gives rise to a U-shaped average cost curve. This is better shown in Fig. (2). This type of market can sustain a competitive market structure where many hospitals can compete taken the price as given and equating it to their marginal cost. In this market structure, hospitals can make profit not only in the short run but in the long run as well. Mills and Schumann [46] have shown that in industries where there exists demand variability even in the long run firms can survive producing at higher than the minimum average cost as long as they are sufficiently flexible. They argued that lower minimum average costs are usually related to larger-sized firms. Smaller firms can survive by absorbing a disproportionate share of output fluctuations. Thus, if they are sufficiently flexible, smaller hospitals can absorb proportionally more unexpected demand than the larger 
hospitals, producing at higher average cost even in the long run and still make a profit.

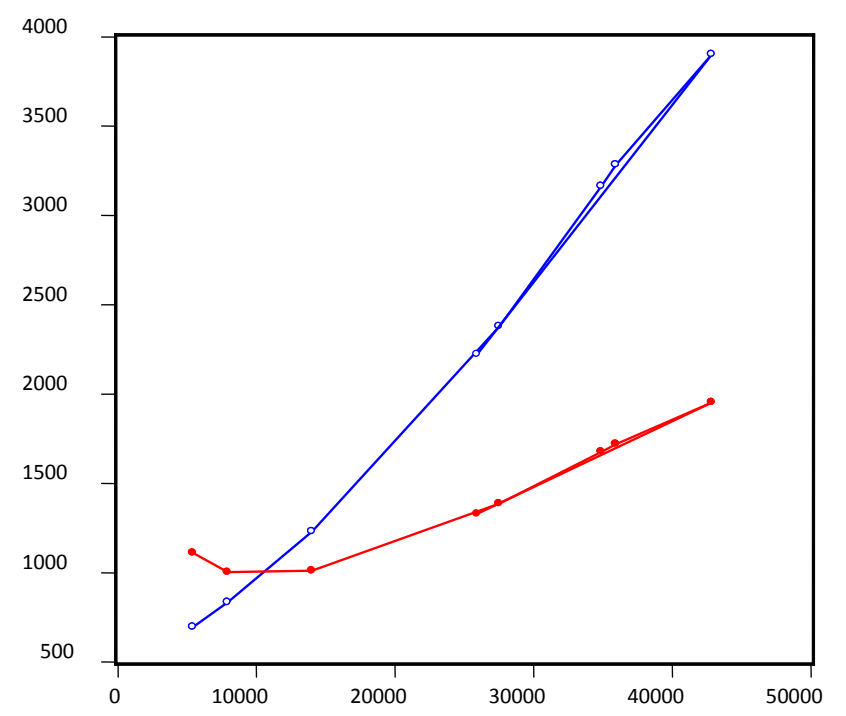

Marginal C ost $\longrightarrow$ A verage C ost

Fig. (2). Average and marginal costs of hospital admissions.

This analysis might justify government intervention because not all firms in the industry are facing the same competitive conditions. In such a case, the perfect competitive pricing rule cannot be applied because the marginal cost is below the average cost at all levels of output. The market fails and one hospital will dominate the market. In this case, government intervention is justified. However, if the hospital market is characterized by demand variability, a portion of which is unexpected, then in the long run the efficiency of perfect competitive market does not hold any more. Firms do not produce at their minimum average cost and this must justify government intervention. This might explain why there are so many pressures in the Greek hospital market to become more private and many investors want to enter the Greek health market. From the above cost analysis it seems that there are considerable profits to be made even in the long run. The industry characteristics are such that small and large firms can survive in both the short and long run. Whether this is desirable is an issue that relates to the nature of the hospital service. If it is considered a public good that should be equitably provided, then public hospitals have a role to play in Greece. This public role can be enhanced, if they produce efficiently, exploiting all economies of scale and scope that might exist in the Greek hospital industry. A word of caution is necessary at this point. The above results are based on public hospitals. It is quite possible that private hospitals in Greece are more efficient than public hospitals because of competitive pressures. However, empirical evidences reported by other studies showed that private hospitals do not appear to be more cost efficient than public hospitals ${ }^{9}$. Rivers and Bae [48] examined hospital competition in major metropolitan areas in the USA. They found that greater competition increases rather than decreases hospital costs.

The economies of scope concept is similar to the concept of economies of scale. The cost efficiency gains resulting from economies of scope are attributed to the expansion of different output types rather than to the expansion of the total output. In this study, economies of scope may exist between emergency and elective admissions, assuming that these are different hospital outputs. If the increase in one type of hospital output decreases the cost of producing the other then economies of scope exist. In the basic regression model, economies of scope are captured by the interaction term. The negative sign indicates that an increase in one output reduces the cost of producing the other.

Most studies that calculate economies of scale and scope find contradictory evidence ${ }^{10}$. The above findings confirm the results reported by Smet [14]. Most of the studies find economies of scale that are quickly exhausted as the hospital size increases. It appears that whatever economies of scale exist are achieved by hospitals of up to 200 beds and hospitals with a beds capacity over 600 beds exhibit diseconomies of scale [14]. These results have been challenged by Simpson [50]. He has argued, providing evidence from California, that a small hospital can enter the market with a capacity of less than 100 beds and efficiently compete with large hospitals. Bed capacity of a public hospital is a policy decision that is usually taken at a centralized level.

\section{CONCLUSIONS}

This paper presents evidence for the impact of unexpected demand on hospital cost in Greece. It extends earlier empirical work that provides a flexible hospital cost function allowing for estimating cost elasticities and marginal costs of emergency and elective admissions as well as the cost of treating an unexpected hospital arrival. The measurement of unexpected hospital demand includes all possible information that can be extracted from the data since it takes into account daily variations of hospital emergency admissions for a sample of ten Greek NHS hospitals for a 5-year period. Our results of marginal costs and scale economies are analogous to the findings of other empirical studies but they differ in the magnitude of impact.

These findings are consistent with the conclusions reached by earlier studies indicating that hospitals respond to unexpected demand by holding reserve capacity. If the hospital cost function is misspecified, then hospitals will

\footnotetext{
${ }^{9}$ Even in the USA where most of the health care is privately provided, hospitals do not promote efficiency. Dafny [47] argued that as long as health care providers can earn non-negative profits, there is very little incentive to reduce costs.

${ }^{10} \mathrm{This}$ is not unique to public hospital cost comparisons but it may also apply to other public services, such as education and welfare. For example, Tresch and Zlate [49] compared economies of scale of three important public services in USA: public higher education, welfare and state psychiatric hospitals. They found evidence of unexploited economies of scale and long run inefficiencies.
} 
appear to be cost inefficient by incurring a higher cost by not fully using stand-by capacity. If holding reserve capacity is an efficient response to demand uncertainty, then reimbursement and regulatory policies should be adjusted to account for such hospital cost structures. The evidence resulted in this study verifies this hypothesis. Uncertainty of demand has a positive impact on Greek average hospital costs.

\section{ACKNOWLEDGEMENTS}

I would like to thank the Greek National Scholarship Foundation (IKY) for its financial support to my postgraduate studies. Also, I thank very much Professor Ann Netten, University of Kent, UK, Professor Alastair Gray, University of Oxford, UK and an anonymous referee for their guidance and their support.

\section{CONFLICT OF INTEREST}

None declared.

\section{REFERENCES}

[1] Baker LC, Phibbs CS, Guarino C, Supina D, Reynolds JL. Withinyear variation in hospital utilization and its implications for hospital costs. J Health Econ 2004; 23: 191-211.

[2] Joskow PL. The effects of competition and regulation on hospital bed supply and the reservation quality of the hospital. Rand J Econ 1980; 11: 421-47.

[3] Linares C, Diaz J. Impact of high temperatures on hospital admissions: comparative analysis with previous studies about mortality (Madrid). Eur J Public Health 2008; 18(3): 317-22.

[4] Diaz J, Alberdi JC, Pajares MS, et al. A model for forecasting emergency hospital admissions: effect of environmental variables. J Environ Health 2001; 64(3): 9-15.

[5] Hussain S, Harrison R, Ayres J, et al. Estimating and forecasting hospital admissions due to influenza: planning for winter pressure the case of the West Midlands, UK. J Appl Stat 2005; 32(3): 191205.

[6] Abdel-Aal RE, Mangoud AM. Modeling and forecasting monthly patient volume at a primary health care clinic using univariate timeseries analysis. Comput Methods Prog Biomed 1998; 56: 235-47.

[7] Fullerton KJ, Crawford VLS. The winter bed crisis - quantifying seasonal effects on hospital bed usage. Q J Med 1999; 92(4): 199206

[8] Upshur REG, Moineddin R, Crighton E, Kiefer L, Mamdani M. Simplicity within complexity: seasonality and predictability of hospital admissions in the province of Ontario 1988-2001 - a population-based analysis. BMC Health Serv Res 2005; 5(1): 13.

[9] Atun RA, Samyshkin YA, Drobniewski F, et al. Seasonal variation and hospital utilization for tuberculosis in Russia: hospitals as social care institutions. Eur J Public Health 2005; 15: 350-4.

[10] Jones SA, Joy MP, Pearson J. Forecasting demand of emergency care. Health Care Manage Sci 2002; 5: 297-305.

[11] Friedman B, Pauly MV. A new approach to hospital cost functions and some issues in revenue regulation. Health Care Financ Rev 1981; 4(3): 105-14.

[12] Friedman B, Pauly MV. Cost functions for a service firm with variable quality and stochastic demand: the case of hospitals. Rev Econ Stat 1983; 63: 620-4.

[13] Carey K. Stochastic demand for hospitals and optimising 'excess' bed capacity. J Regul Econ 1998; 14(2): 165-87.

[14] Smet M. Cost characteristics of hospitals. Soc Sci Med 2007; 55(6): 895-906.

[15] Hughes D, McGuire A. Stochastic demand, production responses and hospital costs. J Health Econ 2003; 22(6): 999-1010.

[16] Lynk WJ. The creation of economic efficiencies in hospital mergers. J Health Econ 1995; 14(5): 507-30.

[17] Bagust A, Place M, Posnett J. Dynamics of bed use in accommodating emergency admissions stochastic simulation model. BMJ 1999; 319: 155-8.

[18] Knox Lovell CA, Rodriguez-Alvarez A, Wall A. The effects of stochastic demand and expense preference behavior on public hospital costs and excess capacity. Health Econ 2008; 18(2): 22735.

[19] Rodriguez-Alvarez A, Knox Lovell CA. Excess capacity and expense preference behavior in National Health Systems: an application to the Spanish public hospitals. Health Econ 2004; 13(2): 157-69.

[20] McPake B, Kumaranayake L, Normand C. Health economics - an international perspective. London, England: Routledge 2002.

[21] Gaynor M, Anderson G. Uncertain demand, the structure of hospital costs and the cost of an empty bed. J Health Econ 1995; 14: 291-317.

[22] Boutsioli Z. Measuring unexpected hospital demand: the application of a univariate model to public hospitals in Greece. Hosp Top 2009; 87(4): 14-21.

[23] Jones SS, Evans RS, Allen TL, et al. A multivariate time series approach to modelling and forecasting demand in the emergency department. J Biomed Inform 2009; 42: 123-39.

[24] Aletras V, Kontodimopoulos N, Zagoldoudis A, Niakas D. The short-term effect on technical and scale efficiency of establishing regional health systems and general management in Greek NHS hospitals. Health Policy 2007; 83: 236-45.

[25] Carpenter M. On the edge: the fate of progressive modernization in Greek health policy. Int Polit Sci Rev 2003; 24(2): 257-72.

[26] Mossialos E, Allin S, Karras K, Davaki K. An investigation of caesarean sections in three Greek hospitals. Eur J Public Health 2005; 15(3): 288-95.

[27] Tountas Y, Karnaki P, Pavi E. Reforming the reform: the Greek National Health System in transition. Health Policy 2002; 62: 1529.

[28] Katharaki M. Approaching the management of hospital units with an operational research technique: the case of 32 Greek obstetric and gynaecology public units. Health Policy 2008; 85: 19-31.

[29] Athanassopoulos AD, Gounaris C. Assesing the technical and allocative efficiency of hospital operations in Greece and its resource allocation implications. Eur J Oper Res 2001; 133: 41631.

[30] Giokas DI. Greek hospitals: how well their resources are used. Omega 2001; 29: 73-83.

[31] Athanassopoulos AD, Gounaris C, Sissouras A. A descriptive assessment of the production and cost efficiency of general hospitals in Greece. Health Care Manage Sci 1999; 2: 97-106.

[32] Hisnanick JJ. Forecasting the demand for inpatient services for specific chronic conditions. J Med Syst 1994; 18: 9-21.

[33] Ghosh S, Das A. Short-run electricity demand forecasts in Maharashtra. Appl Econ 2002; 34(8): 1055-9.

[34] Lee S, Fambro DB. Application of subset autoregressive integrated moving average model for short-term freeway traffic volume forecasting. Transport Res Record: J Transport Res Board 1999; 1678: 179-88.

[35] Chamlin MB. Crime and arrests: An autoregressive integrated moving average (ARIMA) approach. J Quant Criminol 1988; 4(3): 247-58.

[36] Chatfield C. The analysis of time series - an introduction. $6^{\text {th }}$ ed. New York: Chapman and Hall/CRC 2004

[37] Anderson O. Time series analysis and forecasting - the BoxJenkins approach. London: Butterworths 1976.

[38] Keeler TE, Ying JS. Hospital costs and excess bed capacity: a statistical analysis. Rev Econ Stat 1996; 78(3): 470-81.

[39] Grannemann TW, Brown RS, Pauly MV. Estimating hospital costs: a multiple-output analysis. J Health Econ 1986; 5: 107-27.

[40] Carey K. A panel data design for estimation of hospital cost functions. Rev Econ Stat 1997; 79(3): 443-53.

[41] Liaropoulos LL, Siskou O, Kaitelidou D, Theodorou M, Katostaras T Informal payments in public hospitals in Greece. Health Policy 2008; 87(1): 72-81.

[42] Aletras VH. A comparison of hospital scale effects in short run and long run cost functions. Health Econ 1999; 8(6): 521-30.

[43] Farsi M, Filippini M. Effects of ownership, subsidization and teaching activities on hospital costs in Switzerland. Health Econ 2008; 17(3): 335-50.

[44] Caves DW, Christensen LR, Swanson GA. Productivity growth, scale economies, and capacity utilization in US railroads 19551974. Am Econ Rev 1981; 71: 994-1002.

[45] Adang EMM, Wensing M. Economic barriers to implementation of innovations in health care: is the long run - short run efficiency discrepancy a paradox? Health Policy 2008; 88(2): 236-42. 
[46] Mills DE, Schumann L. Industry structure with fluctuating demand. Am Econ Rev 1985; 75(4): 758-67.

[47] Dafny LS. How do hospitals respond to price changes? AEM 2005; 95(5): 1525-47.

[48] Rivers PA, Bae S. Hospital competition in major US metropolitan areas: an empirical evidence. J Socio-Econ 1999; 28: 597-606.
[49] Tresch R, Zlate A. Explorations into the production of state government services: education, welfare and hospitals. Boston College Working Papers in Economics 2007.

[50] Simpson J. A note on entry by small hospitals. J Health Econ 1995; 14: $107-13$.

Received: August 17, 2011

Revised: October 27, 2011

Accepted: October 27, 2011

(C) Zoe Boutsioli; Licensee Bentham Open.

This is an open access article licensed under the terms of the Creative Commons Attribution Non-Commercial License (http://creativecommons.org/licenses/by$\mathrm{nc} / 3.0 /$ ) which permits unrestricted, non-commercial use, distribution and reproduction in any medium, provided the work is properly cited. 